\title{
Improving mechanical properties of AlSi10Mg aluminum alloy using ultrasonic melt treatment combined with T6 heat treatment
}

\author{
F. Vatansever, A. T. Ertürk*, S. Karabay \\ Mechanical Engineering Department, Engineering Faculty, Kocaeli University, Izmit-Kocaeli, Turkey
}

Received 12 July 2018, received in revised form 8 October 2018, accepted 15 October 2018

\begin{abstract}
The purpose of this study is examining the effects of ultrasonic melt treatment on microstructure and mechanical properties of the AlSi10Mg alloy. In this study, ultrasonic melt treatment with different frequencies and duration was applied to AlSi10Mg molten alloy. Also, T6 heat treatment was applied to samples which were obtained by ultrasonic melt treatment (UST) with different application parameters to investigate the combination of T6 heat treatment and UST effect on the microstructure and mechanical properties. The microstructure of cast samples was characterized by optical and scanning electron microscopy. Also, hardness and tensile tests were carried out. The results indicate that primary $\alpha$-Al phases are transformed from coarse dendrites to smaller dendrites by the ultrasonic melt treatment. Besides, secondary dendrite arm spacing of the alloy decreased and mechanical properties such as hardness and tensile strength increased. UST reduces the secondary dendrite arm spacing (SDAS) of the aluminum alloy to $50 \%$. Additionally, increasing treatment time contributes to hardness up to $12 \%$ and tensile strength up to $50 \%$.
\end{abstract}

K e y w or d s: grain refining, ultrasonic melt treatment, aluminum alloys, mechanical properties

\section{Introduction}

Aluminum is the most important secondary metal that comes after steel, increasingly used in many sectors such as automotive, aerospace, machinery, manufacturing, transportation, construction, packaging, conductor wire production, and household appliances due to its lightweight, mechanical, physical, corrosion properties and many other reasons. Parallel to the rapidly developing technology, expectations of the qualification of materials are also increasing. Over the several past decade's grain refinement has been mostly applied for enhancing the microstructural and mechanical properties of aluminum alloys through physical and chemical methods such as severe plastic deformation, mechanical alloying, conventional thermomechanical processing, and adding grain refiners $[1-$ 5]. Ultrasonic vibration $(20 \mathrm{kHz}-1 \mathrm{GHz}$ frequencies $)$ application is a relatively new method compared to the other methods used to improve the mechanical properties of materials. UST is used to improve the microstructure and mechanical properties of alloys in metallurgy. Even though initial experiments of using UST at the laboratory level for processing molten alloys were based on the 1940s and first industrial experiments in the 1950-60s, the method has not yet been used in mass production. In the last 15 years, there has been a great increase in the researches related to the UST depending on the technological developments on modeling techniques and producibility of more advanced manufacturing equipment $[6,7]$.

Researchers implemented UST with mostly similar parametric approaches. In melting stage, $0.2-1 \mathrm{~kg}$ of weight alloy in a crucible was heated in an electric oven and melted. In the next stage, ultrasonic vibration was applied to melt in a pot for $10-1200 \mathrm{~s}$ at $580-750^{\circ} \mathrm{C}$. In general, a molten alloy was subjected to ultrasonic vibration in mainly two different cases as above the liquidus temperature (liquid state) and during solidification (nucleation of $\alpha$-Al phase and eutectic transformation). At last stage, the melt was poured into a crucible made by graphite, copper or steel molds

*Corresponding author: tel.: +90-262-3033402; fax: +90-262-3033003; e-mail address: tamererturk@gmail.com 
Ta ble 1. Previously studied conditions of UST for Al-Si alloys

\begin{tabular}{|c|c|c|c|c|c|}
\hline Material & $\begin{array}{l}\text { Frequency } \\
\qquad(\mathrm{kHz})\end{array}$ & Treatment time & $\begin{array}{l}\text { Amplitude } \\
\quad(\mu \mathrm{m})\end{array}$ & $\begin{array}{c}\text { Power } \\
(\mathrm{kW})\end{array}$ & $\begin{array}{c}\text { Radiator } \\
\text { (Sonotrode) }\end{array}$ \\
\hline $\operatorname{AlSi} 9 \mathrm{Cu} 3(\mathrm{Fe})[8]$ & $19.8 \pm 0.25$ & From 680 to $580^{\circ} \mathrm{C}$ & - & $0.2,0.4,0.6$ & Ti6Al4V \\
\hline A390 [9] & 20 & $0-1200 \mathrm{~s}$ & - & 0.84 & - \\
\hline $\mathrm{Al}-23 \% \mathrm{Si}[10]$ & 20 & $600 \mathrm{~s}$ & 4 & 0.05 & Indirect UST \\
\hline Different Al-Si alloys [11] & 20 & $120 \mathrm{~s}$ & - & 0.26 & - \\
\hline $\mathrm{Al}-7 \% \mathrm{Si}$ and $\mathrm{Al}-16 \% \mathrm{Si}[12]$ & 20 & $\begin{array}{l}\text { From } 750^{\circ} \mathrm{C} \text { to } \\
\text { solidification }\end{array}$ & 25 & - & Ti6Al4V \\
\hline $\mathrm{Al}-17 \% \mathrm{Si}[13]$ & $20 \pm 1$ & During DC casting & 48 & 2 & Ceramic \\
\hline $\begin{array}{l}\mathrm{Al}-12.2 \mathrm{Si}-3.3 \mathrm{Cu}-2.4 \mathrm{Ni}-0.8 \mathrm{Mg}- \\
-0.1 \mathrm{Fe}[14]\end{array}$ & 19 & $60 \mathrm{~s}$ & 20 & - & Titanium \\
\hline $\mathrm{Al}-8 \% \mathrm{Si}[15]$ & 20 & $\begin{array}{l}\text { Liquid, nucleation and } \\
\text { growth and eutectic } \\
\text { transformation states }\end{array}$ & - & 0.5 & - \\
\hline A390 [16] & 20 & $30 \mathrm{~s}$ & - & 1 & - \\
\hline LM6 [17] & 20 & $\begin{array}{l}\text { From } 750^{\circ} \mathrm{C} \text { to } \\
\text { solidification }\end{array}$ & 25 & - & Ti6Al4V \\
\hline $\mathrm{Al}-12 \% \mathrm{Si}-2 \% \mathrm{Fe}[18]$ & 20 & $60,120 \mathrm{~s}$ & - & 0.27 & - \\
\hline AlSi9Cu3 [19] & $19.8 \pm 0.25$ & $120 \mathrm{~s}$ & - & $0.2,0.4,0.6$ & Ti6Al4V \\
\hline A356 [20] & 20 & $\begin{array}{l}\text { From } 630^{\circ} \mathrm{C} \text { to } \\
\text { solidification }\end{array}$ & 56.7 & 1.5 & Ti6Al4V \\
\hline Al-Si alloy (Etial-195) [21] & 40 & $25,30,40,50 \mathrm{~s}$ & - & 0.5 & Indirect UST \\
\hline Different Al-Si alloys [22] & - & $\begin{array}{l}10 \mathrm{~s} \text {, liquid state, } \\
\text { solidification range }\end{array}$ & 40 & 4 & Niobium \\
\hline
\end{tabular}

and solidified under atmospheric conditions. As seen in Table 1, many researchers conducted studies on the effects of UST at a frequency of $19-40 \mathrm{kHz}$ with an amplitude of $4-56.7 \mu \mathrm{m}$ and at a power of $0.05-4 \mathrm{~kW}$ conditions to various alloys by immersing a preheated titanium, ceramic or niobium radiator (sonotrode) into the melt or applying ultrasonic vibration indirectly.

It has been reported at previous studies [8-33] that grain refinement at the microstructure decreased segregation, increased homogeneity, improved mechanical properties (tensile strength, stiffness, elongation at break) and removal of dissolved gases (degassing) were obtained in tested materials by UST. Besides, the ultimate tensile strength and elongation at break increased, and grain size decreased with increasing ultrasonic power [8]. The results have shown that ultrasonic vibration application during solidification of aluminum alloys is more efficient when the transition metals such as Zr and Ti are present in the alloy [23]. Different than extensively examined aluminum alloys, the effects of ultrasonic vibration on the microstructure and mechanical properties on $\mathrm{Mg}-8 \mathrm{Li}-3 \mathrm{Al}$ [24], AS41 [25], Al-4Mg [26] alloys and 35CrMo steel [27] were investigated. Researchers reported that the UST positively affected the microstructure of these materials [24-27].

Researchers have investigated the effects of ultrasonic vibration on different Al-Si alloys. Kotadia et al. 

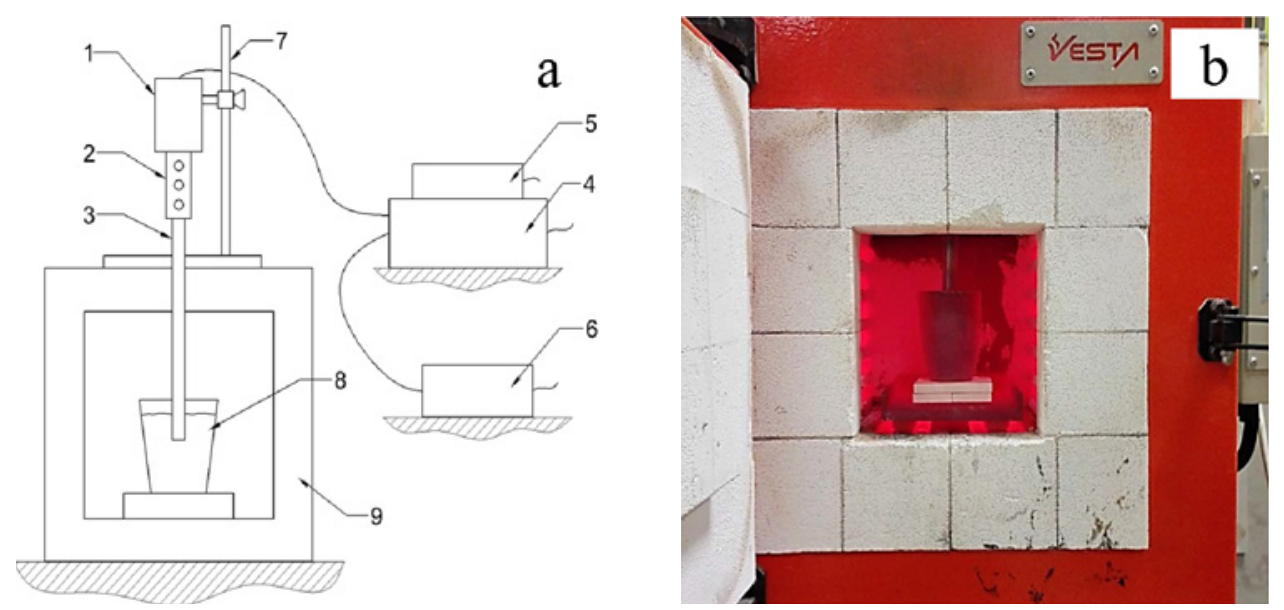

Fig. 1. (a) Schematic of experimental setup: 1 - piezoelectric transducer, 2 - horn, 3 - radiator, 4 - power amplifier, 5 oscilloscope, 6 - ultrasonic function generator, 7 - movable clamp, 8 - graphite crucible, 9 - electrical furnace, and (b) UST application in the electrical furnace.

[12] have investigated the effect of UST during solidification of $\mathrm{Al}-7 \% \mathrm{Si}$ and $\mathrm{Al}-16 \% \mathrm{Si}$ alloys. The results show that dendritic grains of hypoeutectic alloy transformed into equiaxed $\alpha$-Al grains and better dispersion of primary Si particles was obtained for hypereutectic alloy. Wang et al. [15] applied UST to Al-8\% Si alloy at different solidification stages including a fully liquid state, nucleation, and growth of $\alpha$-Al phase and eutectic transformation period. They have shown that UST at all application stages changed eutectic morphology and improved yield strength of the alloy, but the apparent morphological change was observed when UST was directly introduced in the eutectic transformation period. Jian et al. [20] have shown that UST modified the morphology of eutectic silicon of A356 alloy from coarse acicular plate-like form to a finely dispersed rosette-like form and reduced the size of eutectic silicon. Zhang et al. [22] applied UST to Al-Si alloys with 5, 11 and $17 \%$ Si content. According to the results, the grain size of hypoeutectic alloys and the size of primary Si particles of hypereutectic alloy decreased with UST. They also showed that while UST at solidification of hypoeutectic alloys refined grain structure, UST at the liquid phase of hypereutectic alloy was more effective than the application at solidification.

Although there are different studies in the literature related to the UST during the solidification of alloys, liquid state application of UST is limited. There is a scant comprehensive study that examines the effects of vibration frequency and duration on mechanical properties. Also, there is not an extensive study about how T6 heat treatment affects microstructure and mechanical properties of aluminum alloys when applied with UST. In this study, the effects of ultrasonic vibration were investigated to improve the microstructure and hence the mechanical properties of the AlSi10Mg alloy. Further, the combined effects of ultrasonic vibration with T6 heat treatment of the alloy were investigated. For this purpose, ultrasonic vibration was applied to the AlSi10Mg aluminum alloy melt with the frequency of $15,17.5$ and $20 \mathrm{kHz}$ for 0 , 180,300 and $600 \mathrm{~s}$ and the microstructure and mechanical properties of obtained samples were investigated.

\section{Materials and methods}

In this study, the hypoeutectic AlSi10Mg aluminum alloy was used. The experimental setup used in this study mainly consists of a $300 \mathrm{~W}$ power amplifier, a transducer which converts electrical energy to mechanical energy in the form of ultrasonic vibration, a $20 \mathrm{~mm}$ diameter and $400 \mathrm{~mm}$ long Ti6Al4V radiator which transfers ultrasonic energy to molten alloy, and an ultrasonic function generator which enables changing of ultrasonic vibration frequency and amplitude. Rest of the parts of the experimental setup is shown in Fig. 1.

AlSi10Mg aluminum alloy was cut and prepared in $400 \mathrm{~g}$ using a precision scale for every experiment. The alloy was melted at $700{ }^{\circ} \mathrm{C}$ in a graphite crucible using an electrical furnace. The temperature of the molten alloy was controlled using a K-type thermocouple. After that, the Ti6Al4V radiator was put into the electric furnace through a hole at the top of the furnace and preheated at $700^{\circ} \mathrm{C}$ to avoid thermal shock and temperature drop of the melt. After preheating the radiator was dipped into the molten alloy by $30 \mathrm{~mm}$ below the melt surface. Different ultrasonic vibration with $15,17.5,20 \mathrm{kHz}$ frequency was applied for 180 , 300 and $600 \mathrm{~s}$ isothermally at $700^{\circ} \mathrm{C}$. The amplitude of ultrasonic vibration is measured as $6 \mu \mathrm{m}$ by Keyence LC-2420 laser displacement sensor. Experimental conditions are given in Table 2.

After the application of ultrasonic treatment, the 
Table 2. Experimental conditions of the study

Testing \& specimen conditions

\begin{tabular}{|c|c|c|c|}
\hline Specimen number & Mold temperature $\left({ }^{\circ} \mathrm{C}\right)$ & Diameter $(\mathrm{mm})$ & Heat treatment \\
\hline 1 & 23 & $\varnothing 15$ & - \\
\hline 2 & 23 & $\varnothing 10$ & - \\
\hline 3 & 300 & $\varnothing 15$ & - \\
\hline 4 & 300 & $\varnothing 15$ & $\mathrm{~T} 6$ \\
\hline \multicolumn{4}{|c|}{ Parameters of UST } \\
\hline \multicolumn{2}{|c|}{ Ultrasonic melt treatment time $(\mathrm{s})$} & \multicolumn{2}{|l|}{$0,180,300,600$} \\
\hline \multicolumn{2}{|c|}{ Vibration frequency $(\mathrm{kHz})$} & \multicolumn{2}{|l|}{$15,17.5,20$} \\
\hline \multicolumn{2}{|c|}{ Vibration amplitude $(\mu \mathrm{m})$} & \multicolumn{2}{|l|}{6} \\
\hline \multicolumn{2}{|c|}{ Melting temperature $\left({ }^{\circ} \mathrm{C}\right)$} & \multicolumn{2}{|c|}{700} \\
\hline \multicolumn{2}{|c|}{ Cooling rate $\left({ }^{\circ} \mathrm{C} \mathrm{s}^{-1}\right)$} & \multicolumn{2}{|c|}{3.7 (cold mold) -1.53 (hot mold) } \\
\hline \multicolumn{2}{|c|}{ Weight of molten alloy (g) } & \multicolumn{2}{|c|}{400} \\
\hline \multicolumn{2}{|c|}{ Radiator diameter (mm) } & \multicolumn{2}{|l|}{20} \\
\hline \multicolumn{2}{|c|}{ Immersed length of the radiator ( $\mathrm{mm})$} & \multicolumn{2}{|l|}{30} \\
\hline
\end{tabular}

Parameters of T6 heat treatment [35]

Solutionizing: $530 \pm 5^{\circ} \mathrm{C}, 6 \mathrm{~h}$

Artificial aging: $160 \pm 5^{\circ} \mathrm{C}, 12 \mathrm{~h}$

Ta ble 3. Chemical composition, physical and mechanical properties of tested alloy [35]

\begin{tabular}{|c|c|c|c|c|c|c|c|c|}
\hline \multicolumn{9}{|c|}{ Chemical composition of tested alloy } \\
\hline $\mathrm{Si}$ & $\mathrm{Fe}$ & $\mathrm{Cu}$ & $\mathrm{Mn}$ & $\mathrm{Mg}$ & $\mathrm{Ti}$ & $\mathrm{Ni}$ & $\mathrm{Zn}$ & $\mathrm{Sn}$ \\
\hline \multirow[t]{2}{*}{10.7} & 0.285 & 0.001 & 0.343 & 0.287 & 0.06 & 0.03 & 0.01 & 0.004 \\
\hline & & & \multicolumn{6}{|c|}{ Physical and mechanical properties } \\
\hline \multicolumn{5}{|c|}{$\begin{array}{l}\text { Density }\left(\mathrm{g} \mathrm{cm}^{-3}\right) \\
\text { Melting range }\left({ }^{\circ} \mathrm{C}\right) \\
\text { Modulus of elasticity }\left(\mathrm{N} \mathrm{mm}^{-2}\right) \\
\text { Thermal conductivity at } 25^{\circ} \mathrm{C}\left(\mathrm{W} \mathrm{cm}^{-1} \mathrm{~K}^{-1}\right)\end{array}$} & \multicolumn{3}{|c|}{$\begin{array}{l}2.68 \\
555-590 \\
74535 \\
1.39-1.60\end{array}$} & \\
\hline \multicolumn{5}{|c|}{ UTS $\left(\mathrm{N} \mathrm{mm}^{-2}\right)$} & Elc & $\mathrm{n}(\%)$ & \multicolumn{2}{|c|}{ Brinell hardness } \\
\hline \multicolumn{3}{|c|}{ Sand castings } & & 157 & \multicolumn{2}{|c|}{3.5} & \multicolumn{2}{|c|}{60} \\
\hline \multirow{3}{*}{\multicolumn{2}{|c|}{ Permanent mold castings }} & & & 215 & \multicolumn{2}{|c|}{2} & \multicolumn{2}{|c|}{85} \\
\hline & & & & 176 & \multicolumn{2}{|c|}{3} & \multicolumn{2}{|c|}{70} \\
\hline & & & & 245 & \multicolumn{2}{|c|}{3} & \multicolumn{2}{|c|}{70} \\
\hline
\end{tabular}

radiator was taken out from molten alloy. The alloy was poured into two different steel molds $\varnothing 10$ and $\varnothing 15 \mathrm{~mm}$. This procedure was repeated without ultrasonic vibration to observe the effect on the microstructure of the cast alloy. Solidified alloys were cut to $10 \mathrm{~mm}$ height. All the samples were sanded with different $\mathrm{SiC}$ papers from 300 to 2400 grids. After that, obtained samples were polished with 6 and $1 \mu \mathrm{m}$ diamond paste respectively followed by final polishing using $0.06 \mu \mathrm{m}$ colloidal silica suspension. Polished specimens were immersed into Keller's etchant for $30 \mathrm{~s}$ and washed with alcohol to neutralize resid- ual of the etchant. Finally, microstructure examination was characterized by optical and scanning electron microscopes and mechanical properties were measured by tensile and hardness tests. The tensile test was performed according to ASTM B557M-10. The tensile test specimens were manufactured by a CNC lathe, having a gauge length of $30 \mathrm{~mm}$ and a diameter of $6 \mathrm{~mm}$. Brinell hardness of the alloys was measured according to ASTM E-10 using a $\varnothing 2.5 \mathrm{~mm}$ diameter ball indenter under a load of $62.5 \mathrm{kgf}$. Physical and mechanical properties of the tested alloy are listed in Table 3 . 

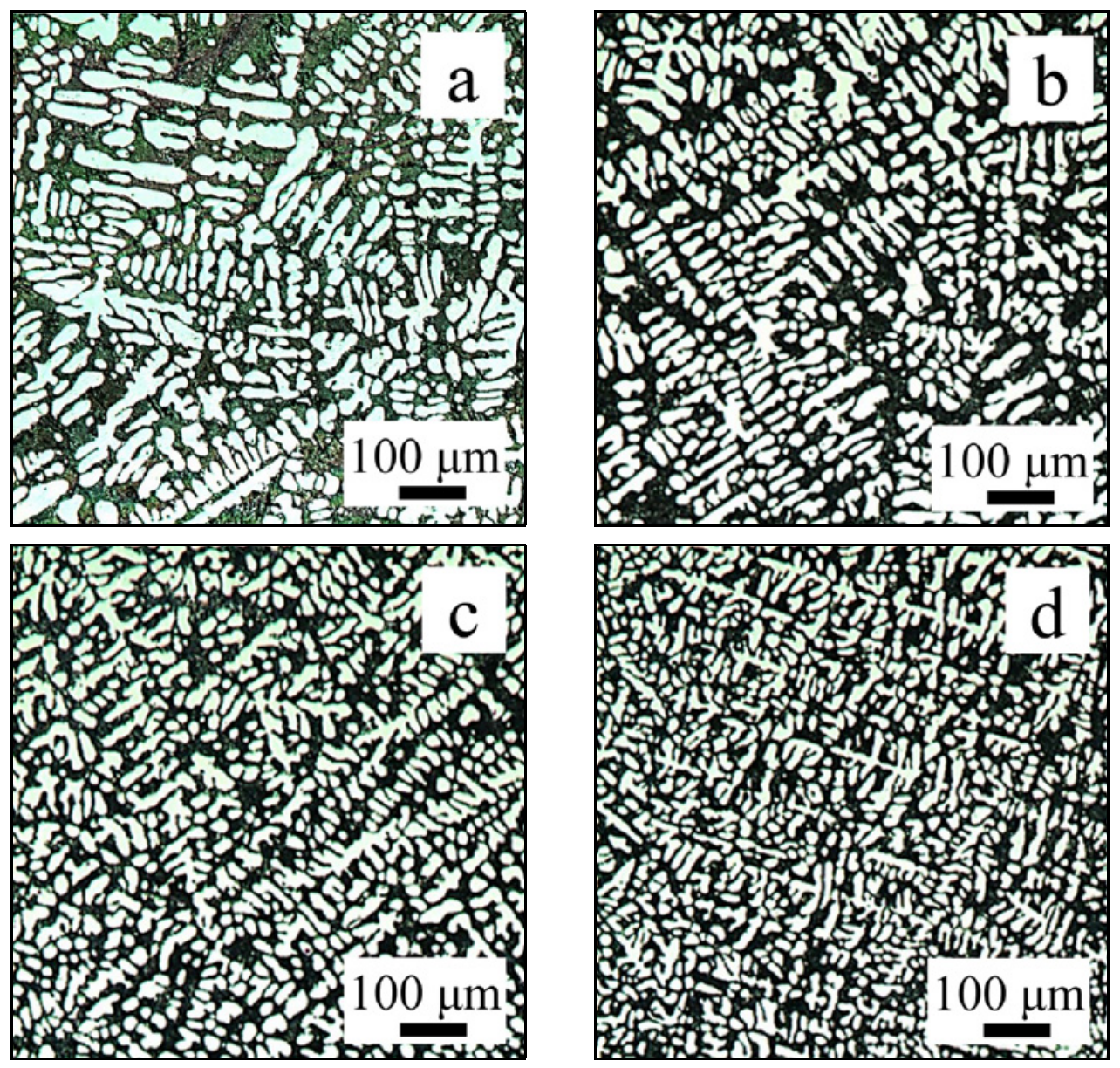

Fig. 2a-d. Microstructures after $15 \mathrm{kHz}$ UST with diameter cold mold $\varnothing 15 \mathrm{~mm}$ : (a) untreated, (b) $180 \mathrm{~s}$, (c) $300 \mathrm{~s}$, and (d) $600 \mathrm{~s}$.

\section{Results}

\subsection{Microstructure}

More than 700 optical and scanning electron microscope images were analyzed to investigate the effect of UST on the microstructure of AlSi10Mg alloy. Selected microstructures of the $\varnothing 15 \mathrm{~mm}$ diameter cold mold samples produced by UST and as-cast are shown in Figs. 2a-d. The untreated alloy consists of a coarsegrained microstructure containing $\alpha$-Al dendrites with a maximum size of $100 \mu \mathrm{m}$ as observed in Fig. 2a. It is also distinctly seen that in Figs. $2 b-d$ the coarse $\alpha$-Al dendrites are fragmented and distributed relatively homogeneously in the eutectic phase depending on the increasing application period from 180 to $600 \mathrm{~s}$ at a frequency of $15 \mathrm{kHz}$.

Relatively coarse-grained dendrites are distributed heterogeneously in the microstructure of the $\varnothing 10 \mathrm{~mm}$ diameter cold mold sample obtained without ultrasonic vibration in Fig. 2e. Microstructures obtained with different ultrasonic vibration frequencies (15, 17.5 and $20 \mathrm{kHz}$ ) of the $\varnothing 10 \mathrm{~mm}$ diameter cold mold samples can be seen in Figs. $2 \mathrm{f}-\mathrm{h}$. The micrographs show that after $300 \mathrm{~s}$ UST almost all the prior dendrites were disintegrated to the structure. Different frequency values caused a little difference in the disintegration of the prior dendrites (see Figs. $2 \mathrm{f}-\mathrm{h}$ ). It is therefore not surprising that no important difference was found between the mechanical properties of these samples. Haghayeghi et al. [28] reported that the application at 17.5 and $20 \mathrm{kHz}$ reduced the grain size and porosity, while 10 and $14 \mathrm{kHz}$ did not cause any change because these frequencies did not outnumber the cavitation threshold of the AA7075 aluminum alloy. The presented research results show that grain refinement was achieved by applying all frequency values. Also, the rapid cooling condition of the $\varnothing 10 \mathrm{~mm}$ diameter mold results in thinner microstructure than the $\varnothing 15 \mathrm{~mm}$ diameter mold.

By the effect of the $\mathrm{T} 6$ heat treatment shown in Fig. 3a, the microstructure consisting of fragmented and dispersed $\alpha$-Al dendrites in the eutectic phase was unlikely to be detected in Figs. 2a,e. Besides, Figs. 3b$\mathrm{d}$ show the microstructures of the $\varnothing 15 \mathrm{~mm}$ diameter hot mold samples obtained by a combination of T6 heat treatment and UST with a frequency of $20 \mathrm{kHz}$. The combined effect of coexistent UST and T6 heat 

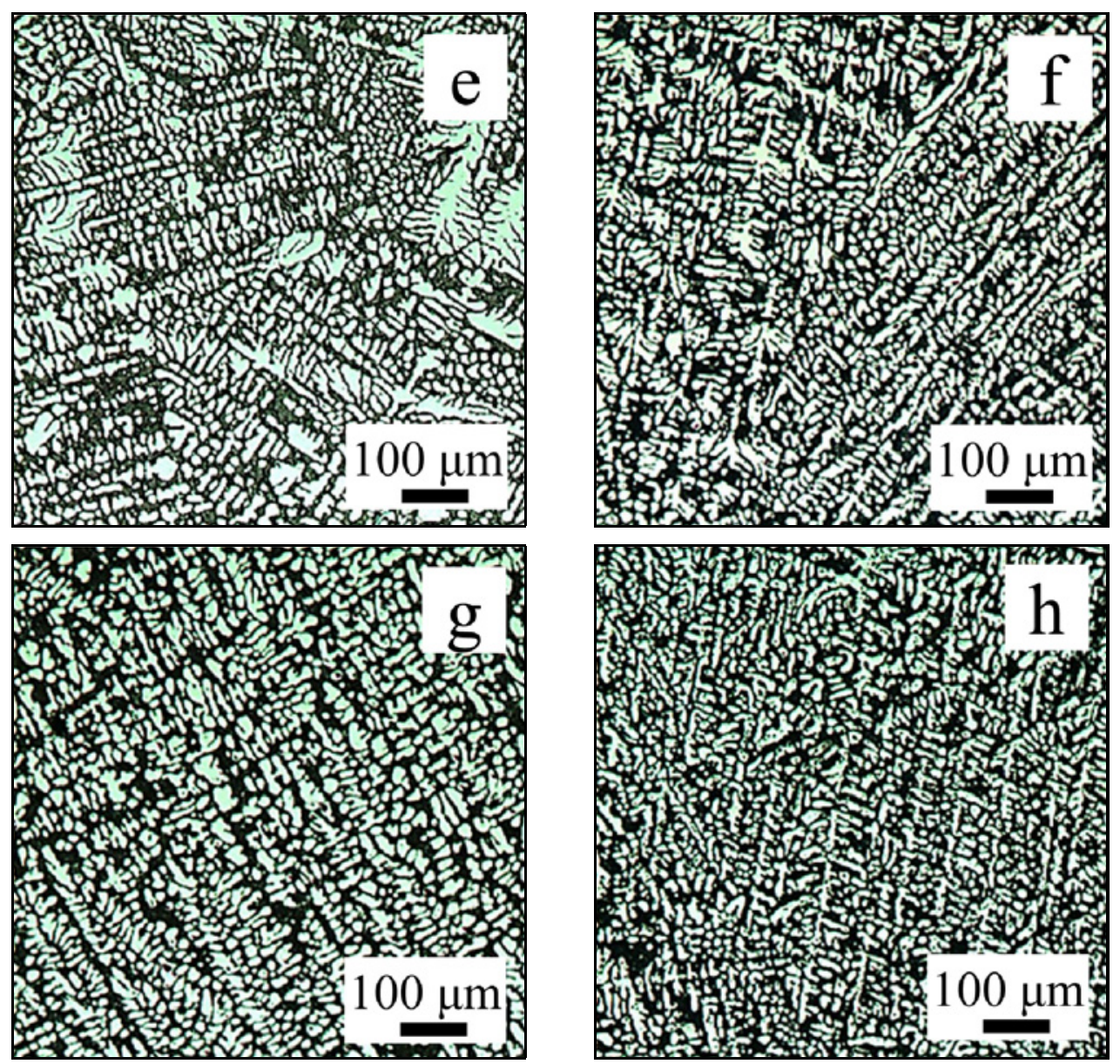

Fig. 2e-h. Microstructures after $300 \mathrm{~s}$ UST with diameter cold mold $\varnothing 10 \mathrm{~mm}$; (e) untreated, (f) 15, (g) 17.5, and (h) $20 \mathrm{kHz}$ frequency.

treatment application on $\mathrm{AlSi} 10 \mathrm{Mg}$ alloy is observed as evolving time-dependent size reduction from 180 to $600 \mathrm{~s}$ (see Figs. 3b-d) of both $\alpha$-Al and eutectic phases, exhibiting a close homogeneous distribution within each other.

The resulting microstructures after UST with a frequency of $15 \mathrm{kHz}$ for 180 and $300 \mathrm{~s}$ are given in Fig. 4. According to the micrographs, dendrites become smaller and spread better into the microstructure of AlSi10Mg alloy by the increasing UST time. In addition to this, it has been found that the eutectic silicon phase shrinks similarly and spreads better in the microstructure with the increasing application time. These microstructural results of the UST application on AlSi10Mg alloy correspond with previous researches $[11,14,16,17,20]$. UST on hyper-eutectic Al-23\% Si alloy reduced coarse primary silicon and $\alpha$ $\mathrm{Al}$ phase size and diffused silicon phase more homogeneously into the structure [10]. UST caused a transformation of the primary $\alpha$-Al phase from dendrite to fine globular form $[17,19,22]$ and shortened the length of the eutectic silicon plates in hypo-eutectic Al-Si alloys [12, 17, 19, 20].

To evaluate the microstructure, the distance be- tween secondary dendrite arms, as a criterion, in evaluating materials exhibiting dendritic microstructure was also measured. SDAS values of the samples obtained by different UST conditions are presented in Fig. 5. It is clear that the UST application reduces SDAS with increasing treatment time for all frequencies and samples. It is furthermore detected that the $\varnothing 15$ and $\varnothing 10 \mathrm{~mm}$ diameter cold mold samples have a similar, nearly linear decreasing characteristic whereas the $\varnothing 15 \mathrm{~mm}$ diameter hot mold samples show a sudden decrease for $180 \mathrm{~s}$ application period of UST and then a decrease of SDAS becomes relatively lower with increasing treatment time. It is also observed that the SDAS values of $\varnothing 10 \mathrm{~mm}$ diameter size samples are lower when compared to $\varnothing 15 \mathrm{~mm}$ in cold mold. It can be said that this case is due to the samples of $\varnothing 10 \mathrm{~mm}$ diameter size have smaller cross-sectional area than the $\varnothing 15 \mathrm{~mm}$ diameter samples and therefore solidify faster. Furthermore, owing to the lower cooling rate the distances between the secondary dendrite arms of the hot mold samples are higher than those of cold mold samples.

In the previous studies, many researchers found out that UST modified the microstructure by providing 

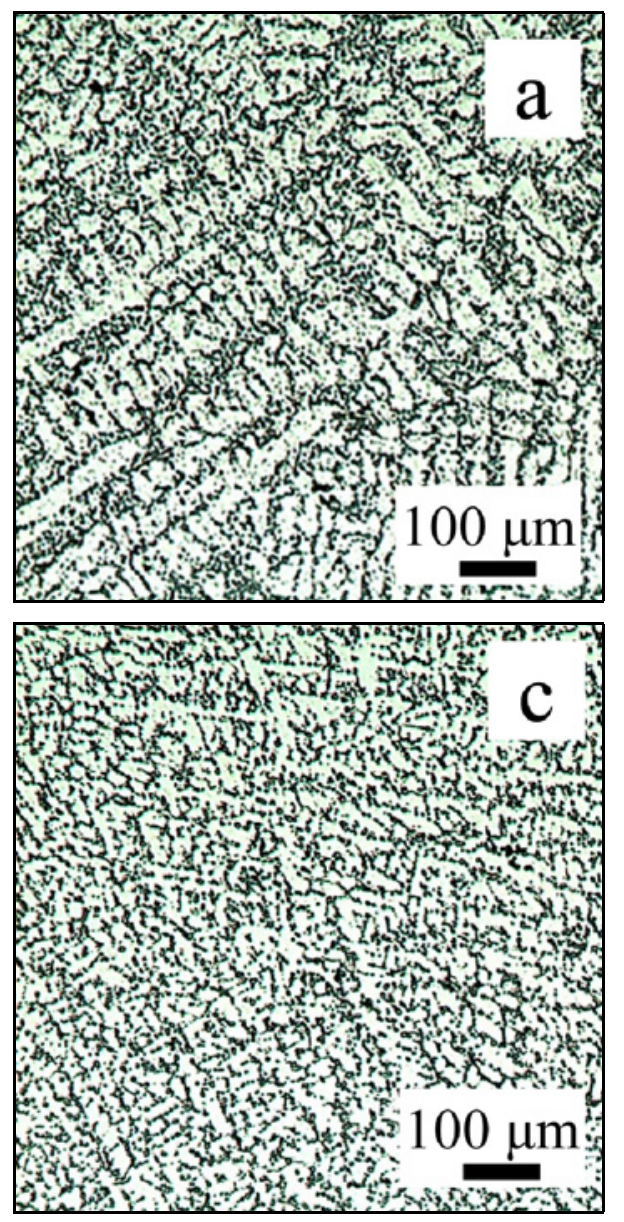
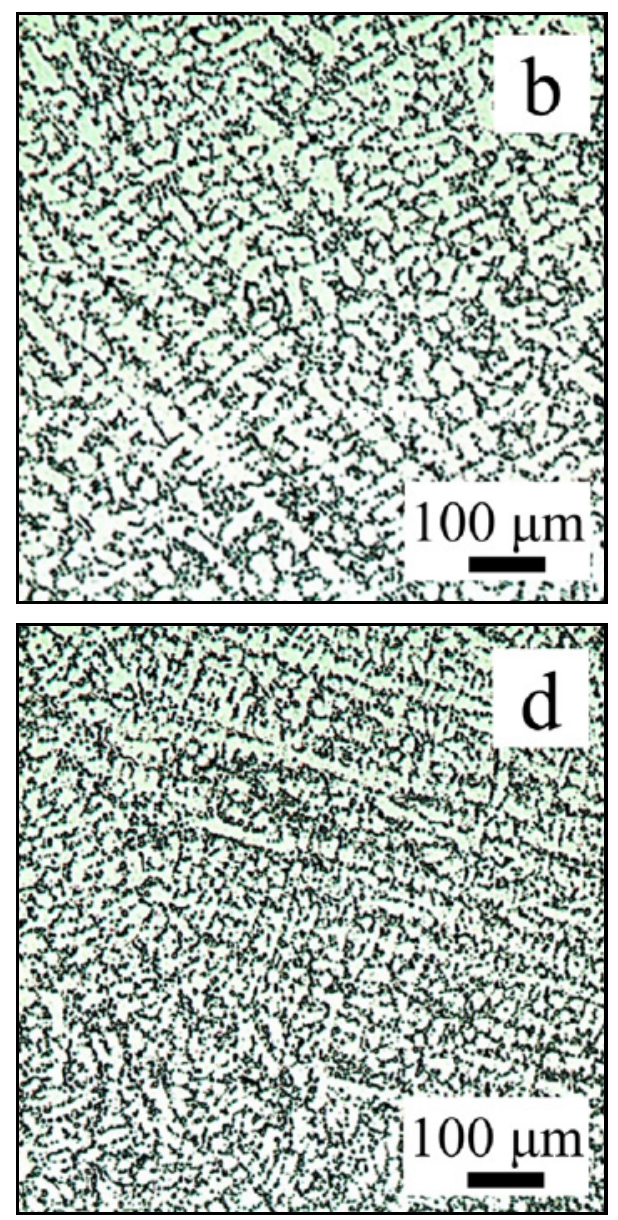

Fig. 3. Microstructures after $20 \mathrm{kHz}$ UST with diameter hot mold $\varnothing 15 \mathrm{~mm}$ and T6 heat treatment: (a) untreated, (b) $180 \mathrm{~s},(\mathrm{c}) 300 \mathrm{~s}$ and (d) $600 \mathrm{~s}$.
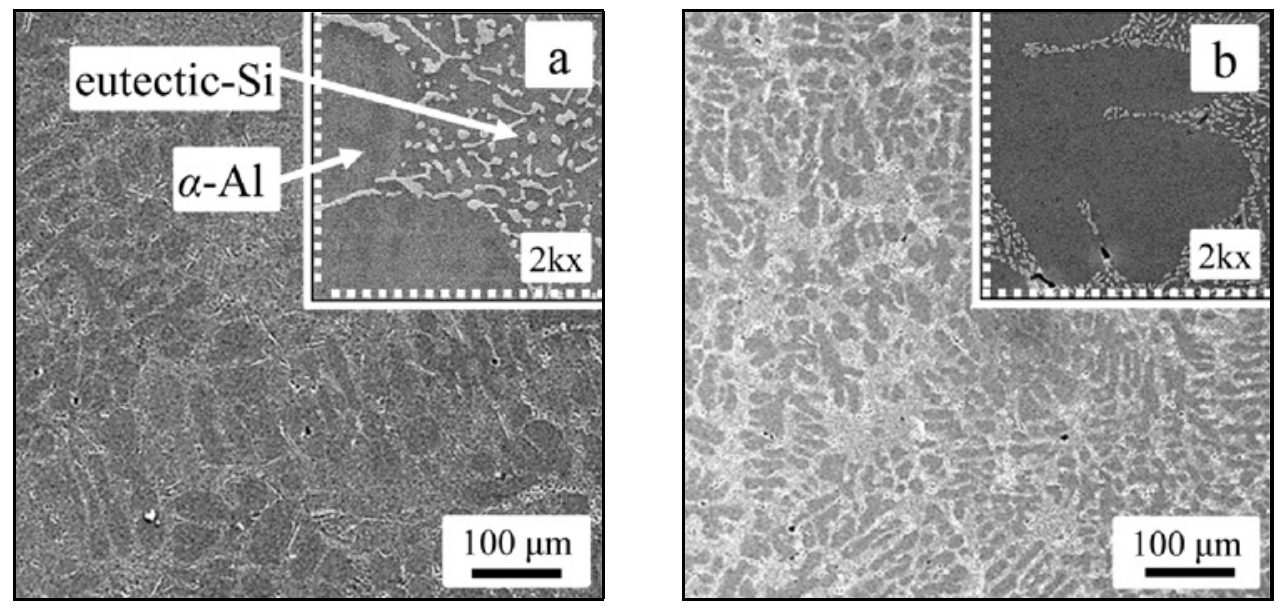

Fig. 4. SEM micrographs of the $\varnothing 15 \mathrm{~mm}$ diameter cold mold samples at $15 \mathrm{kHz}$ frequency for (a) $180 \mathrm{~s}$ and (b) $300 \mathrm{~s}$.

smaller dendrites, equiaxial and globular grains [834]. In addition to this, Yao et al. [24], Patel et al. [25] and Ruirun et al. [32] showed that grain size of $\mathrm{Mg}$ 8Li-3Al, AS41 and TiAl alloys decreased by increasing treatment time. Our investigation results verify these researchers' findings in this manner.

\subsection{Mechanical properties}

It is known that the mechanical properties of materials are directly affected by microstructure. While fine-grained microstructure develops mechanical properties, coarse-grained microstructure affects them ad- 


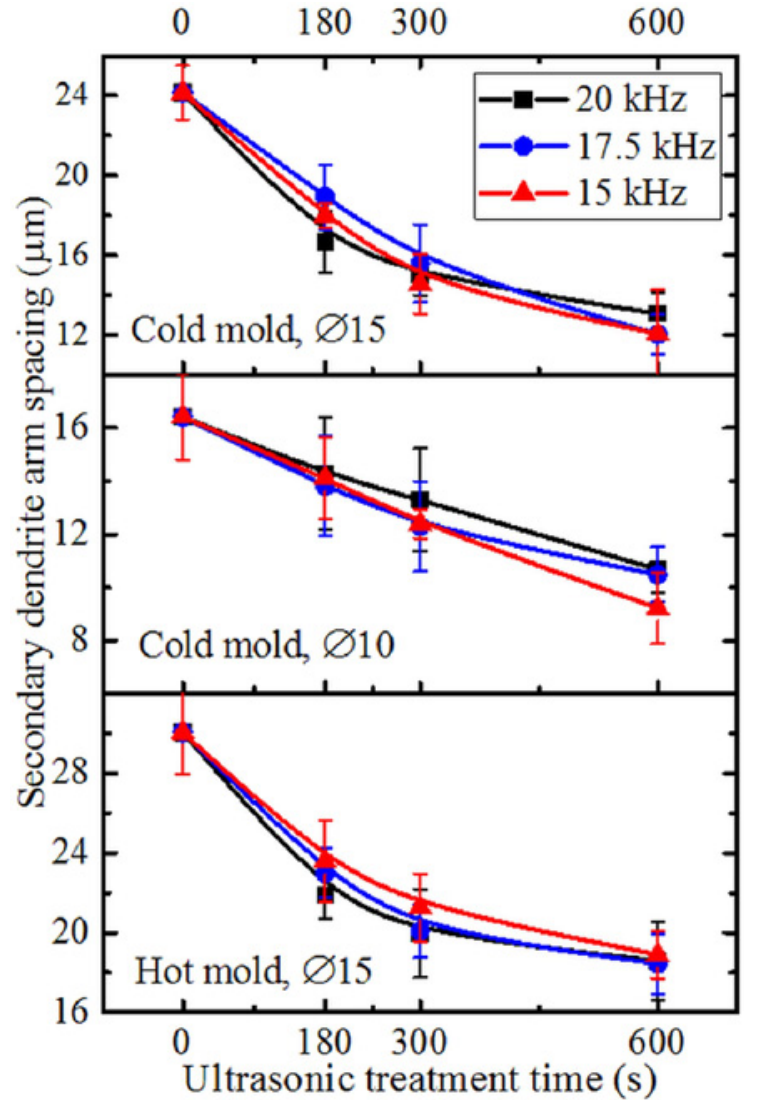

Fig. 5. Secondary dendrite arm spacing values of samples treated with different ultrasonic parameters.

versely. Hardness and tensile test measurements were carried out to determine the effect of UST on the mechanical properties of the AlSi10Mg alloy.

Figure 6(a) shows the tensile strength values of $\varnothing$ $15 \mathrm{~mm}$ diameter hot mold samples with the effect of UST combined with T6 heat treatment. The tensile strength value without UST and T6 heat treatment of $\varnothing 15 \mathrm{~mm}$ diameter hot mold sample was $133 \mathrm{MPa}$. This value is increased after UST for $600 \mathrm{~s}$ to $152.8 \mathrm{MPa}$ for $15 \mathrm{kHz}, 174.8 \mathrm{MPa}$ for $17.5 \mathrm{kHz}$ and $205.6 \mathrm{MPa}$ for $20 \mathrm{kHz}$. It can be inferred from Fig. 6a that UST with all frequencies linearly increases the tensile strength up to $180 \mathrm{~s}$. However, after this period UST causes a nearly linear decreasing trend of the tensile strength.

The tensile strength of the $\varnothing 15 \mathrm{~mm}$ diameter hot mold sample subjected to T6 heat treatment without UST was 187.29 MPa. After performing UST for $600 \mathrm{~s}$ and T6 heat treatment, the tensile strength of the $\varnothing 15 \mathrm{~mm}$ diameter hot mold sample rose to $216.3 \mathrm{MPa}$ for $15 \mathrm{kHz}, 258.2 \mathrm{MPa}$ for $17.5 \mathrm{kHz}$ and $293.59 \mathrm{MPa}$ for $20 \mathrm{kHz}$. When the combined effect of UST and T6 heat treatment is examined, it can be expressed that the tensile strength values for all treatment frequencies increase in a wavy pattern. The reason for fluctuating increase in curves is thought to be due to some defect in the tensile specimens. It has also been found that the T6 heat treatment application increases the tensile strength even without UST. In the case of combining two applications the maximum value of the tensile strength is obtained. Similar results were previously reported that ultrasonic vibration caused an increase of the tensile strength of A390 [9], near-eutectic Al-Si [14], AlSi9Cu3 [19], Mg-8Li-3Al [24], AA7075 [28] alloys.

All hardness values of the test samples were increased by UST for all frequencies with increasing treatment time as shown in Fig. 6b. Hardness increment changes similarly for all samples. As a numerical example of the hardness increment, while the hardness of the $\varnothing 10 \mathrm{~mm}$ diameter cold mold samples without ultrasonic treatment was $84.9 \mathrm{HB}$, the UST for $600 \mathrm{~s}$ increased hardness to $90.03 \mathrm{HB}$ for $15 \mathrm{kHz}, 89.37 \mathrm{HB}$ for $17.5 \mathrm{kHz}$ and $90.03 \mathrm{HB}$ for $20 \mathrm{kHz}$.

As hardness test results of the $\varnothing 10$ and $\varnothing 15 \mathrm{~mm}$ diameter samples with cold mold are analyzed, while the hardness increases for $300 \mathrm{~s}$ at all three frequency values, the increasing rate after $300 \mathrm{~s}$ reduces significantly. Accordingly, it can be said that UST for more than $300 \mathrm{~s}$ does not cause an important change in the hardness of these samples. Although the hardness value of $\varnothing 15 \mathrm{~mm}$ diameter samples with hot mold increases linearly for $600 \mathrm{~s}$ with frequencies of 15 and $17.5 \mathrm{kHz}$, UST does not cause a severe change in hardness after $300 \mathrm{~s}$ for $20 \mathrm{kHz}$ frequency. In addition to these results, it is seen that the hardness values of hot mold are generally lower than the cold mold samples since the $300^{\circ} \mathrm{C}$ mold temperature causes slow cooling. As a result, it was determined that the hardness of all samples increased at different ratios by ultrasonic vibration application. Both ultrasonic and T6 heat treated $\varnothing 15 \mathrm{~mm}$ diameter hot mold samples have maximum hardness values about $114 \mathrm{HB}$. The reason for the increase in hardness is thought to be the modification of microstructure by UST. Similar results were reported by Unal et al. [21] that ultrasonic treatment favorably affected hyper-eutectic cast Al-Si alloy hardness values and provided an increase of 15-20\%. Also, Zhai et al. [31] and Ruirun et al. [32] reported that the application of ultrasonic vibration increased micro-hardness of aluminum alloys.

\section{Discussion}

According to the obtained results, the primary Al phase evolved from coarse dendrites into nearly equiaxed grains. Meanwhile, UST application at the liquid state resulted in global - equiaxed grains in previous researches $[11,15,19]$. Therefore, it has been provided that the $\alpha$-Al dendrites transform into equiaxial grains when the ultrasonic vibration is applied entirely in the liquid phase. 

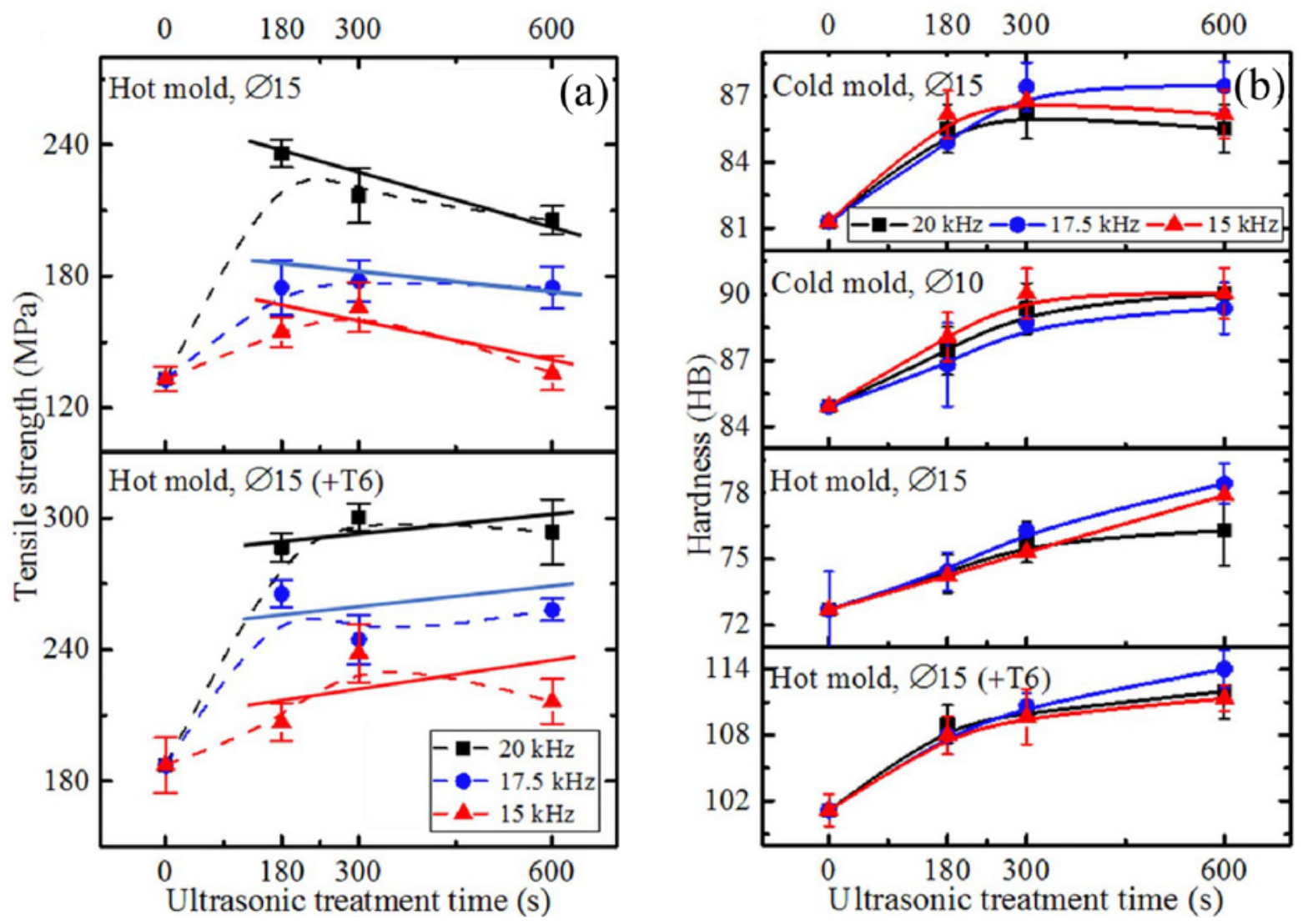

Fig. 6. Time and frequency dependent effect of UST: (a) tensile strength and (b) hardness.

It has been inferred that the primary sources of refining primary $\mathrm{Al}$ phase and changes in microstructure concerning the phase transformation and morphological evolution of alloys by UST are the collapse of small cavities, dendritic fragmentation, and wetting due to the cavitation-induced nucleation mechanism. As some researchers demonstrated, the improvements in microstructure and mechanical properties arise from cavitation induced heterogeneous nucleation $[8,12,17,19,29-31,33,34]$ and fragmentation of the dendritic structure $[15,22,23,25]$ due to ultrasonic vibration. As previously mentioned in this study, ultrasonic vibration was applied at a fully liquid state (at $700{ }^{\circ} \mathrm{C}$ ) of AlSi10Mg alloy. At the liquid phase, no dendrites occurred inherently. For this reason, it is thought that cavitation induced heterogeneous nucleation is the main mechanism for refining the microstructure of $\mathrm{AlSi} 10 \mathrm{Mg}$ alloy in this study.

Three possible different grain refinement mechanisms in UST are consequently explained by assembling information from previous studies and our investigation:

I. The first one is cavitation induced heterogeneous nucleation, which is described below: Ultrasonic wave produces cavitation. Cavitation induces local high undercooling which results in nucleation. The alternating pressure of ultrasound above the cavitation threshold creates extra unstable and continuously growing gas bubbles [8]. The swollen gas bubbles at negative acoustic (tensile force) half-period (see in Fig. 7) of the ultrasonic wave absorb the thermal energy from the melt-bubble interface. Positive acoustic pressure (compression force) in a half-period of ultrasonic wave causes instantaneous imploding of bubbles. Arising of local melting temperature point due to a bubble collapse locally causes undercooling of the liquid. Thus, nuclei are created by increasing the melting point at a bubble surface. A cavitation bubble collapse causes breaking of oxide layer due to the energetic shock waves (see Fig. 7) [29]. Nucleation is localized in the vicinity of impurities. The role of bubbles is identical to that of chemical grain modifier elements. Cavitation-induced high undercooling and fragmentation creates refined primary aluminum phase.

II. The second one is cavitation-induced dendrite fragmentation and grain multiplication. Bubble collapsing generates shock waves and sharp transient pressure spikes (up to $5 \mathrm{GPa}$ ) [15, 30]. An acoustic stream of the shock waves scatters the nucleation throughout the melt, breaks dendrite arms and single crystals [11]. On the other hand, shock waves can 


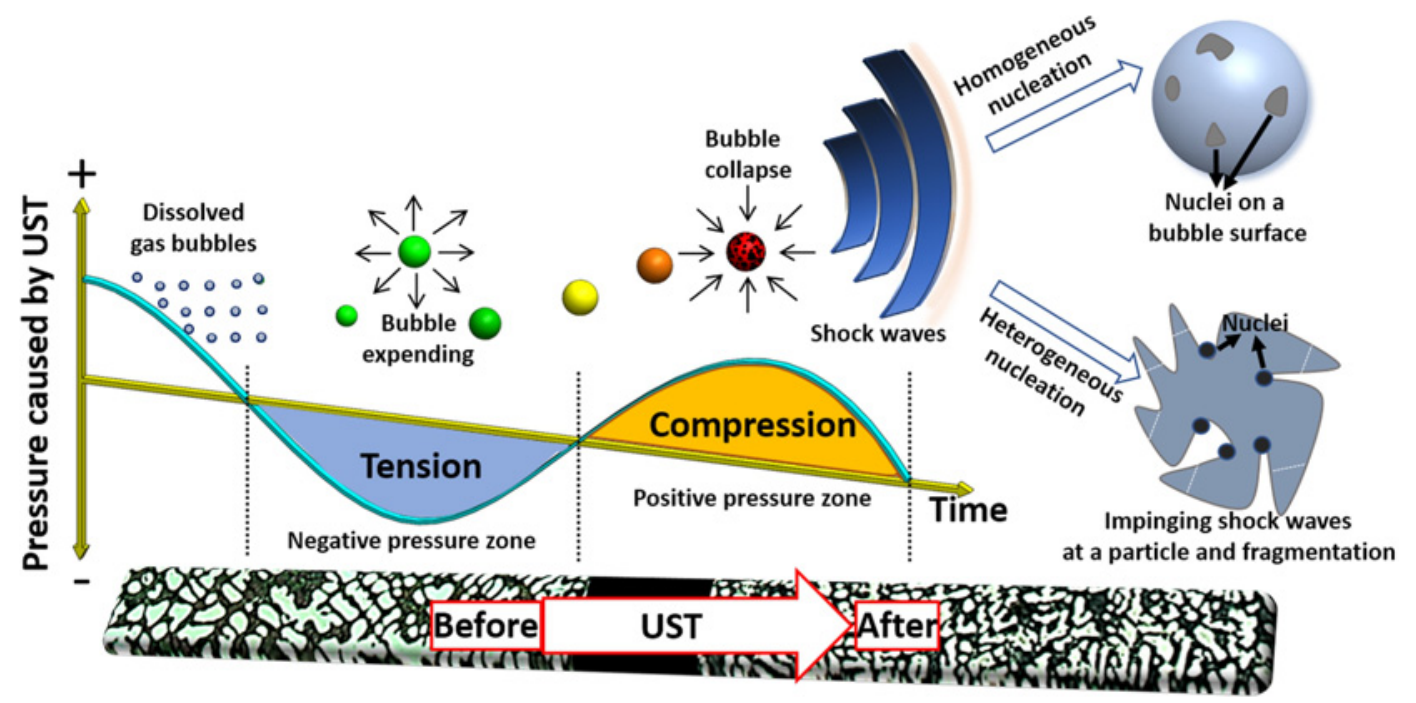

Fig. 7. Schematic diagram of grain refinement and nucleation mechanisms in UST.

result in homogeneous nucleation by promoting undercooling (see in Fig. 7) [11]. Pressure pulse leads to a local elevation in melting temperature $[15,30]$. Thus, locally freezing liquid phase causes globular grains in solute fields. Changing liquidus temperature with pressure PL can be calculated by the Clausius-Clapeyron equation $[15,36]$ :

$$
T_{\text {liquidus }}=T_{\text {melting }}+\frac{T_{\text {melting }} \Delta V}{\Delta H_{\mathrm{m}}}\left(P_{\text {liquidus }}-P_{0}\right),
$$

where $P_{0}$ is atmospheric pressure, $\Delta V$ and $\Delta H_{\mathrm{m}}$ are the volume and enthalpy changes in the liquid-solid transformation [15, 36]. Cavitation induced dendrite fragmentation solely happens provided that the melt includes solid fraction volume. Contrarily to that cavitation enhanced heterogeneous nucleation occurs in liquid alloys.

III. The third one is a vibration-stimulated separation of wall crystals: According to this theory, UST increases the wettability of the mold wall with an alloy which promotes the nucleation of the alloy from mold to center [29]. Theoretical approach of Marangoni convection (MC) is that an imbalance of surface tension on a liquid interface causes capillary motion. The temperature gradient of cooling melt can be driven by the $\mathrm{MC}$ of a spherical liquid-liquid interface under reduced gravity conditions with UST. The MC causes directional solidification from the mold wall to the center of the molten alloy. The motion $\left(V_{\mathrm{M}}\right)$ independently of solidification direction can be described as [31]:

$$
V_{\mathrm{M}}=\frac{-K_{1} r}{\left(2 K_{1}-K_{2}\right)\left(2 U_{1}-3 U_{2}\right)} \frac{\partial \sigma}{\partial T} \frac{\partial T}{\partial x},
$$

where $K$ values are the thermal conductivity, $U$ values are the viscosities of the parent and secondary liquids, $r$ is the secondary liquid droplet radius, $\partial \sigma / \partial T$ and $\partial T / \partial x$ are interfacial energy gradient and temperature gradient, respectively.

\section{Conclusions}

Following conclusions can be drawn:

- Microstructural examination and experimental results show that UST improves microstructure and mechanical properties of the AlSi10Mg alloy. The reason for this improvement is the evolution of primary $\alpha$-Al phase from coarse dendrites to smaller dendrites. Also, the acicular eutectic-Si phase became smaller by the effect of UST. It is concluded that the predominant refinement mechanism was cavitation induced heterogenous nucleation because of pressure and temperature fluctuations.

- Modification of microstructure and mechanical properties of the alloy increased with increasing UST time for all frequencies and samples. However, no significant effect of UST frequency on microstructure and mechanical properties has been observed.

- The UST brings an increase in hardness and tensile strength until the application period of $300 \mathrm{~s}$ for all frequencies, but the vibration applied after $300 \mathrm{~s}$ does not significantly influence hardness and tensile strength of the material.

- Maximum hardness tensile strength is obtained with the combined UST and T6 heat treatment application.

\section{Acknowledgement}

The authors gratefully acknowledge the support of the Scientific Research Coordination Foundation (BAP Unit, Project No. 2017/002) of Kocaeli University. 


\section{References}

[1] Maung, K. N., Yoshida, T., Liu, G., Lwin, C. M., Muller, D. B., Hashimoto, S.: Resour. Conserv. Recycl., 126, 2017, p. 34 . doi:10.1016/j.resconrec.2017.06.016

[2] Karabay, S., Ertürk, A. T., Zeren, M., Yamanoglu, R., Karakulak, E.: Eng. Fail. Anal., 83, 2018, p. 47. doi:10.1016/i.engfailanal.2017.09.007

[3] Feyzullahoğlu, E., Ertürk, A. T., Güven, E. A.: Trans. Nonferrous Met. Soc. China, 23, 2013, p. 3575. doi:10.1016/S1003-6326(13)62903-9

[4] Karabay, S., Güven, E. A., Ertürk, A. T.: Eng. Fail. Anal., 31, 2013, p. 153. doi:10.1016/j.engfailanal.2013.02.005

[5] Ertürk, A. T., Şahin, M., Aras, M.: Trans. Indian Inst. Met., 70, 2017, p. 1233. doi:10.1007/s12666-016-0915-7

[6] Eskin, D. G.: Mater. Sci. Forum, 828, 2015, p. 112. doi:10.4028/www.scientific.net/MSF.828-829.112

[7] Eskin, G. I., Eskin, D. G.: Ultrasonic Treatment of Light Alloy Melts. Boca Raton, CRC Press 2015.

[8] Puga, H., Barbosa, J., Costa, S., Ribeiro, J. S., Pinto, A. M. P., Prokic, M.: Mater. Sci. Eng. A, 560, 2013, p. 589. doi:10.1016/i.msea.2012.09.106

[9] Youn, J. I., Kang, B. I., Ko, D. G., Kim, Y. J.: Int. J. Cast. Met. Res., 21, 2008, p. 135. doi:10.1179/136404608X361828

[10] Feng, H. K., Yu, S. R., Li, Y. L., Gong, L. Y.: J. Mater. Process. Technol., 208, 2008, p. 330. doi:10.1016/j.jmatprotec.2007.12.121

[11] Zhang, Y. B., Lu, Y. P., Jie, J. C., Fu, Y., Zhong, D., Li, T.: Trans. Nonferrous Met. Soc. China, 23, 2013, p. 3242. doi:10.1016/S1003-6326(13)62859-9

[12] Kotadia, H. R., Das, A.: J. Alloys Compd., 620, 2015, p. 1. doi:10.1016/j.jallcom.2014.09.089

[13] Komarov, S., Ishiwata, Y., Mikhailov, I.: Metall. Mater. Trans. A Phys. Metall. Mater. Sci., 46, 2015, p. 2876. doi:10.1007/s11661-015-2829-0

[14] Jung, J. G., Lee, S. H., Lee, J. M., Cho, Y. H., Kim, S. H., Yoon, W. H.: Mater. Sci. Eng. A, 669, 2016, p. 187. doi:10.1016/j.msea.2016.05.087

[15] Wang, J. Y., Wang, B. J., Huang, L. F.: J. Mater. Sci. Technol., 33, 2017, p. 1235. doi:10.1016/j.jmst.2017.07.018

[16] Haghayeghi, R., Paula, L. C., Zoqui, E. J.: J. Mater. Eng. Perform., 26, 2017, p. 1900. doi:10.1007/s11665-017-2602-1

[17] Das, A., Kotadia, H. R.: Mater. Chem. Phys., 125, 2011, p. 853. doi:10.1016/j.matchemphys.2010.09.035

[18] Zhang. Y., Jie. J., Gao. Y., Lu, Y., Li, T.: Intermetallics, 42, 2013, p. 120 . doi:10.1016/j.intermet.2013.05.018
[19] Puga, H., Barbosa, J., Costa, S., Ribeiro, J. S., Prokic, M.: J. Mater. Process. Technol., 211, 2011, p. 1729. doi:10.1016/j.jmatprotec.2011.05.012

[20] Jian, X., Meek, T. T., Han, Q.: Scr. Mater., 54, 2006, p. 893. doi:10.1016/j.scriptamat.2005.11.004

[21] Ünal, N., Çamurlu, H. E., Koçak, S., Düztepe, G.: Int. J. Cast. Met. Res., 25, 2012, p. 246. doi:10.1179/1743133612Y.0000000011

[22] Zhang, L., Eskin, D. G., Miroux, A., Katgerman, L.: Light Metals. Hoboken, Wiley 2012. doi:10.1007/978-3-319-48179-1_174

[23] Eskin, D. G., Atamanenko, T. V., Zhang, L., Katgerman, L.: Essent. Readings Light Met., 3, 2013, p. 415. doi:10.1002/9781118647783.ch51

[24] Yao, L., Hao, H., Ji, S. H., Fang, C. F., Zhang, X. G.: Trans. Nonferrous Met. Soc. China, 21, 2011, p. 1241. doi:10.1016/S1003-6326(11)60848-0

[25] Patel, B., Chaudhari, G. P., Bhingole, P. P.: Mater. Lett., 66, 2012, p. 335. doi:10.1016/j.matlet.2011.08.113

[26] Raghu, R., Nampoothiri, J., Kumar, T. S.: Measurement, 129, 2018, p. 389. doi:10.1016/i.measurement.2018.07.056

[27] Liang, G., Shi, C., Zhou, Y., Mao, D.: Metals, 6, 2016, p. 260. doi:10.3390/met6110260

[28] Haghayeghi, R., Heydari, A., Kapranos, P.: Mater. Lett., 153, 2015, p. 175. doi:10.1016/i.matlet.2015.04.034

[29] Tuan, N. Q., Puga, H., Barbosa, J., Pinto, A. M. P.: Met. Mater. Int., 21, 2015, p. 72. doi:10.1007/s12540-015-1008-6

[30] Jiang, R. P., Li, X. Q., Zhang, M.: Met. Mater. Int., 21, 2015, p. 104. doi:10.1007/s12540-015-1012-X

[31] Zhai, W., Liu, H., Zuo, P., Zhu, X., Wei, B.: Prog. Nat. Sci. Mater. Int., 25, 2015, p. 471. doi:10.1016/j.pnsc.2015.10.006

[32] Ruirun, C., Deshuang, Z., Jingjie, G., Tengfei, M., Hongsheng, D., Yanqing, S., Hengzhi, F.: Mater. Sci. Eng. A, 653, 2015, p. 23. doi:10.1016/j.msea.2015.12.001

[33] Lü, S., Wu, S., Lin, C., Hu, Z., An, P.: Mater. Sci. Eng. A, 528, 2011, p. 8635. doi:10.1016/j.msea.2011.08.014

[34] Atamanenko, T. V., Eskin, D. G., Katgerman, L.: Int. J. Cast. Met. Res., 22, 2009, p. 26. doi:10.1179/136404609X367254

[35] Geiser, W.: Aluminium Alloy Tables. Zurich, Alcan S.A. 1982.

[36] Li, J. W., Momono, T., Fu, Y., Zheng, J., Tayu, Y.: Trans. Nonferrous Met. Soc. China, 17, 2007, p. 691. doi:10.1016/S1003-6326(07)60158-7 